\title{
Correction to: Treating primary immunodeficiencies with defects in NK cells: from stem cell therapy to gene editing
}

\author{
C. Eguizabal ${ }^{1,2^{*}}$, L. Herrera ${ }^{1,2}$, M. Inglés-Ferrándiz ${ }^{1,2}$ and J. C. Izpisua Belmonte ${ }^{3}$
}

\author{
Correction to: Stem Cell Res Ther (2020) 11:453 \\ https://doi.org/10.1186/s13287-020-01964-5
}

After publication of our article [1], the authors became aware that they'd omitted acknowledgement of permission to adapt and reproduce Fig. 2 (first published in Current Opinion in Allergy and Clinical Immunology, 2011 [2]) and Fig. 4 (first published in Molecular Therapy, 2017 [3]).

Figure 2 was adapted and published with permission of the Publisher. Original source: Pessach IM and Notarangelo LD. Primary immunodeficiency modeling with induced pluripotent stem cells. Curr Opin Allergy Clin Immunol. 2011 Dec;11(6):505-11. (c) 2011 Wolters Kluwer Health, Inc. https://journals.lww.com/co-allergy/ pages/default.aspx All rights reserved. The Creative Commons license does not apply to this content. Use of the material in any format is prohibited without written permission from the publisher, Wolters Kluwer Health, Inc. Please contact permissions@lww.com for further information.
Figure 4 was adapted and published with permission of the Publisher. Original source: Thrasher AJ and Williams DA. Evolving Gene Therapy in Primary Immunodeficiency. Mol Ther. 2017 May 3;25(5):1132-1141. () 2017 The American Society of Gene and Cell Therapy. All rights reserved.

In addition, a number of reference errors were introduced which are clarified below:

- References 59-87 in the original article (references [3-31] in this correction article) have had their information corrected and also replace the original references for the respective citations in the original article text.

- Reference 37 in the original article (reference [32] in this correction article) has had its information corrected. 


\section{Patient primary cells}

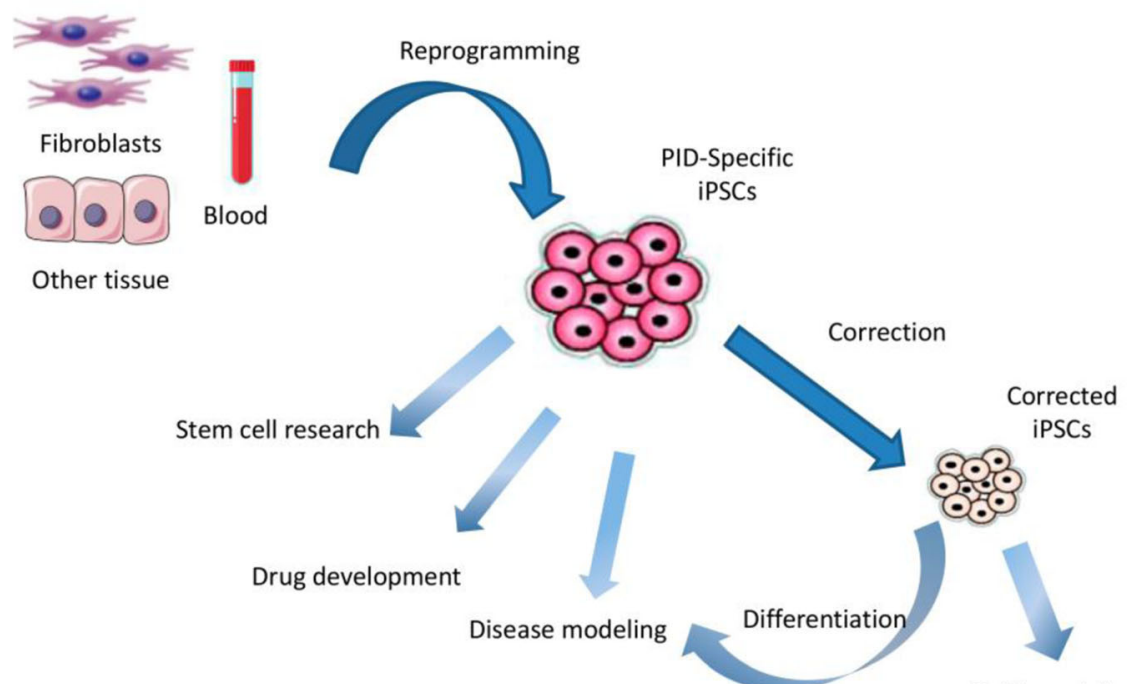

Cell based therapy: HSCs and/or NK cells

Fig. 2 Obtaining hiPS cells from different cell sources in order to use them as a disease model, drug developmental model, or stem cells research. hiPS cells from a PID patient may be corrected with the goal of developing a cell based therapy. Adapted from [37]

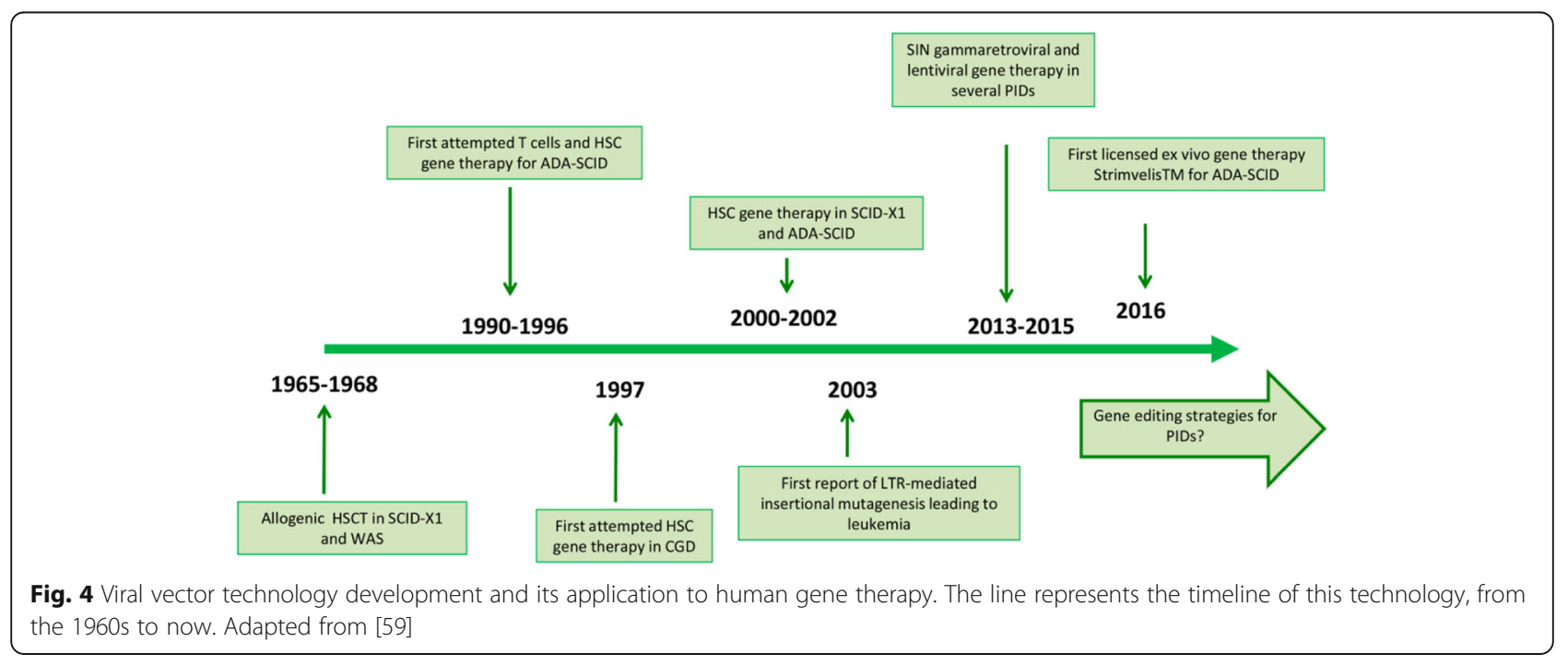




\section{Section: "CURRENT GENE AND CELL THERAPIES FOR PIDS WITH DEFECTS IN NK CELLS”}

Currently, there are very few clinical trials that combine cell and gene therapy that are ongoing for several PIDs as shown in TABLE $2(67,68)$, but none utilize gene-editing strategies.

The triumph of gene therapy in treating PIDs is a major advancement, though limitations in manufacturing disease-specific vectors remain a challenge (69). As this field moves forward, more efficient procedures offering wider spread applications arise. Gene editing defines a group of DNA editing approaches that can be simply designed for point mutations. Recently, programmable nucleases such as ZFNs, TALENs, and CRISPR-Cas9 have been developed as effective methods for editing the genome to correct the affected gene in PIDs (49, 70-75).

Compared to lentiviral vectors, gene-specific editing technologies has become a tremendously promising tool, as it has the potential to physiologically regulate gene expression and prevent genome-wide vector integration. Some of the ongoing efforts are focused on developing sensitive techniques to detect genotoxicity derived from unintended effects of endonucleases (off-target effects).

In the case of CRISPR-Cas9 approaches for HSC genome editing in PIDs, the design of the donor template is challenging and both the nature (single/multiple mutations or deletions in one or more hotspots distributed along the gene) and the functional effect of the mutation (gain of function versus loss of function) have to be taken into consideration (76).

Short donor templates (such as ssODN or linear or plasmid dsDNA donors) have been used to correct loss of function (LOF) mutations of a single or few nucleotides. For example, De Ravin and colleagues (77) could repair the mutation in the $\mathrm{CYBB}$ gene of $\mathrm{CD}^{+} 4^{+} \mathrm{HSCs}$ from patients with the immunodeficiency disorder $\mathrm{X}$ linked chronic granulomatous disease (X-CGD) using a chemically modified $100 \mathrm{bp}$ ssODN that resulted in production of $15-20 \%$ functional mature human myeloid and lymphoid cells for up to 5 months.

In contrast to small mutations, repair of large deletions or insertions is not possible with short donor templates and instead functional complementary DNA (cDNA) templates are inserted to target genes. Encouraging preclinical studies have been published using this approach for the treatment of X-SCID or X-CGD (78-80) and will be ready to translate to clinical trials soon.

However, one limitation to consider for the application of gene editing tools in a clinical setting might be the engraftment efficiency and HSC functionality of genetically modified cells due to cellular effects of the geneediting machinery. Indeed, global gene expression changes have been observed upon delivery of CRISPRCas9 machinery components into the cells. Immune response to viral infection, DNA-damage response, apoptosis and cell cycle processes have been reported as the most significant enriched gene signatures (81). The activation of these biological processes might negatively affect HSC stemness and hematopoietic lineage expansion and differentiation. Further studies are needed in order to better understand these mechanisms and therefore design more efficient CRISPR-Cas9 strategies and improve HSC engraftment efficiency.

Apart from CRISPR-Cas9, other genome editing tools have been used to modify genes in different cell types including HSCs. ZFN and TALEN techniques have been used to modify the IL2RG locus, which is responsible for SCID (82).

Specifically in the case of PID with NK cell defects, a good example of the evolution of treatment approaches is seen with WAS. The first clinical trial with gene therapy in WAS patients was performed using gamma-retroviral vectors. Even if 9 of 10 patients showed partial or complete resolution of immunodeficiency, autoimmunity and other malignancies, 7 of them developed acute leukemia. This study demonstrated that gene therapy for WAS can be effective, although it was essential to find an alternative to gamma-retroviruses given the high risk of leukemia after months or years (83). More recently, self-inactivating lentiviral vectors have shown efficacy for several PIDs, including WAS and they are now in Phase I/II clinical trials for a number of immune disorders. To date, more than 20 patients have been treated using lentiviral vectors and no evidence of vector-related toxicity has been observed with any reports of leukemia (84). However, platelet recovery has been variable in those trials (85). Although no pre-clinical studies have been published yet, nuclease-based gene editing approaches for repairing mutations in PID with NK cell defects might represent the future of gene therapy, already demonstrated by studies targeting other PIDs, as explained above. Hence, WAS gene targeting systems have been already tested in cell lines, providing the first hints for feasibility of CRISPR-based and heterodimeric ZNF-based gene therapy strategies (86).

In summary, thanks to a better understanding of stem cell biology, bone marrow transplantation, vector design and genome editing, it is probable that gene therapy will become the gold standard of care for certain diseases in the future. In fact, its benefits have already been demonstrated for WAS, ADA, SCID and XCGD. In addition, a number of preclinical studies using targeted gene editing strategies show promise $(78-80,86,87)$ and a large number of patients treated so far in clinical trials indicate that the gene therapy field is fast becoming a therapeutic standard. 


\section{Author details}

'Cell Therapy, Stem Cells and Tissues Group, Biocruces Bizkaia Health Research Institute, Barakaldo, Spain. ${ }^{2}$ Research Unit, Basque Center for Blood Transfusion and Human Tissues, Osakidetza, Galdakao, Spain. ${ }^{3}$ Gene Expression Laboratory, The Salk Institute for Biological Studies, 10010 North Torrey Pines Road, La Jolla, California 93027, USA

\section{Published online: 27 April 2021}

\section{References}

1. Eguizabal C, Herrera L, Inglés-Ferrándiz M, Izpisua Belmonte JC. Treating primary immunodeficiencies with defects in NK cells: from stem cell therapy to gene editing. Stem Cell Res Ther. 2020;11(1):453. https://doi.org/10.1186/ s13287-020-01964-5.

2. Pessach IM, Notarangelo LD. Primary immunodeficiency modeling with induced pluripotent stem cells. Curr Opin Allergy Clin Immunol. 2011;11(6): 505-11.

3. Thrasher AJ, Williams DA. Evolving Gene Therapy in Primary Immunodeficiency. Mol Ther. 2017;25(5):1132-41.

4. Buckley RH, Schiff SE, Schiff RI, Markert L, Williams LW, Roberts JL, et al. Hematopoietic stem-cell transplantation for the treatment of severe combined immunodeficiency. N Engl J Med. 1999;340(7):508-16.

5. Antoine C, Müller S, Cant A, Cavazzana-Calvo M, Veys P, Vossen J, et al. Long-term survival and transplantation of haemopoietic stem cells for immunodeficiencies: report of the European experience 1968-99. Lancet. 2003:361(9357):553-60

6. Grunebaum E, Mazzolari E, Porta F, Dallera D, Atkinson A, Reid B, et al. Bone marrow transplantation for severe combined immune deficiency. JAMA. 2006;295(5):508-18.

7. Morgan RA, Gray D, Lomova A, Kohn DB. Hematopoietic stem cell gene therapy: Progress and lessons learned. Cell Stem Cell. 2017;21(5):574-90.

8. Dunbar CE, High KA, Joung JK, Kohn DB, Ozawa K, Sadelain M. Gene therapy comes of age. Science. 2018;359(6372):eaan4672.

9. Ferrua F, Aiuti A. Twenty-five years of gene therapy for ADA-SCID: from bubble babies to an approved drug. Hum Gene Ther. 2017;28(11):972-81.

10. Aiuti A, Roncarolo MG, Naldini L. Gene therapy for ADA-SCID, the first marketing approval of an ex vivo gene therapy in Europe: paving the road for the next generation of advanced therapy medicinal products. EMBO Mol Med. 2017;9(6):737-40.

11. Booth C, Gaspar HB, Thrasher AJ. Treating immunodeficiency through HSC gene therapy. Trends Mol Med. 2016;22(4):317-27.

12. Home - ClinicalTrials.gov [Internet]. [cited 2019 Oct 3]. Available from: https://clinicaltrials.gov/.

13. Poletti V, Charrier S, Corre G, Gjata B, Vignaud A, Zhang F, et al. Preclinical development of a Lentiviral vector for gene therapy of X-linked severe combined immunodeficiency. Mol Ther Methods Clin Dev. 2018;9:257-69.

14. Yeo NC, Chavez A, Lance-Byrne A, Chan Y, Menn D, Milanova D, et al. An enhanced CRISPR repressor for targeted mammalian gene regulation. Nat Methods. 2018;15(8):611-6.

15. Clarke R, Heler R, MacDougall MS, Yeo NC, Chavez A, Regan M, et al. Enhanced Bacterial Immunity and Mammalian Genome Editing via RNAPolymerase-Mediated Dislodging of Cas9 from Double-Strand DNA Breaks. Mol Cell. 2018;71(1):42-55.e8.

16. Genovese P, Schiroli G, Escobar G, Tomaso TD, Firrito C, Calabria A, et al. Targeted genome editing in human repopulating haematopoietic stem cells. Nature. 2014;510(7504):235-40

17. Osborn MJ, Starker CG, McElroy AN, Webber BR, Riddle MJ, Xia L, et al. TALE N-based gene correction for epidermolysis bullosa. Mol Ther. 2013;21(6): 1151-9.

18. Sander JD, Joung JK. CRISPR-Cas systems for editing, regulating and targeting genomes. Nat Biotechnol. 2014;32(4):347-55.

19. Fu Y, Sander JD, Reyon D, Cascio VM, Joung JK. Improving CRISPR-Cas nuclease specificity using truncated guide RNAs. Nat Biotechnol. 2014;32(3): 279-84

20. De Ravin SS, Brault J. CRISPR/Cas9 applications in gene therapy for primary immunodeficiency diseases. Emerg Top Life Sci. 2019;3(3):277-87.

21. De Ravin SS, Li L, Wu X, Choi U, Allen C, Koontz S, et al. CRISPR-Cas9 gene repair of hematopoietic stem cells from patients with $X$-linked chronic granulomatous disease. Sci Transl Med. 2017;9(372).
22. Kuo CY, Long JD, Campo-Fernandez B, de Oliveira S, Cooper AR, Romero Z, et al. Site-Specific Gene Editing of Human Hematopoietic Stem Cells for XLinked Hyper-lgM Syndrome. Cell Rep. 2018;23(9):2606-16.

23. De Ravin SS, Reik A, Liu P-Q, Li L, Wu X, Su L, et al. Targeted gene addition in human CD34(+) hematopoietic cells for correction of X-linked chronic granulomatous disease. Nat Biotechnol. 2016;34(4):424-9.

24. Schiroli G, Ferrari S, Conway A, Jacob A, Capo V, Albano L, et al. Preclinical modeling highlights the therapeutic potential of hematopoietic stem cell gene editing for correction of SCID-X1. Sci Transl Med. 2017;9(411): eaan0820.

25. Cromer MK, Vaidyanathan S, Ryan DE, Curry B, Lucas AB, Camarena J, et al. Global Transcriptional Response to CRISPR/Cas9-AAV6-Based Genome Editing in CD34+ Hematopoietic Stem and Progenitor Cells. Mol Ther. 2018; 26(10):2431-42.

26. Li H, Yang Y, Hong W, Huang M, Wu M, Zhao X. Applications of genome editing technology in the targeted therapy of human diseases: mechanisms, advances and prospects. Signal Transduct Targeted Ther. 2020;5(1):1-23.

27. Braun CJ, Boztug K, Paruzynski A, Witzel M, Schwarzer A, Rothe M, et al. Gene therapy for Wiskott-Aldrich syndrome--long-term efficacy and genotoxicity. Sci Transl Med. 2014;6(227):227ra33.

28. Abina SH-B, Gaspar HB, Blondeau J, Caccavelli L, Charrier S, Buckland K, et al. Outcomes following gene therapy in patients with severe Wiskott-Aldrich syndrome. JAMA. 2015;313(15):1550-63.

29. Zhang Z-Y, Thrasher AJ, Zhang F. Gene therapy and genome editing for primary immunodeficiency diseases. Genes Dis. 2020;7(1):38-51.

30. Gutierrez-Guerrero A, Sanchez-Hernandez S, Galvani G, Pinedo-Gomez J, Martin-Guerra R, Sanchez-Gilabert A, et al. Comparison of zinc finger nucleases versus CRISPR-specific nucleases for genome editing of the Wiskott-Aldrich syndrome locus. Hum Gene Ther. 2018;29(3):366-80.

31. Lyu C, Shen J, Wang R, Gu H, Zhang J, Xue F, et al. Targeted genome engineering in human induced pluripotent stem cells from patients with hemophilia B using the CRISPR-Cas9 system. Stem Cell Res Ther. 2018;9(1): 92.

32. Pessach IM, Notarangelo LD. Primary immunodeficiency modeling with induced pluripotent stem cells. Curr Opin Allergy Clin Immunol. 2011;11(6): $505-11$ 